\title{
A Review of Psychodynamic Perspectives on Working With Children, Families, and Schools
}

\author{
James McNinch
}

\section{University of Regina}

An old friend who now lives in Ottawa calls me on the phone to talk. He tells me about a relationship he struck with an English guy on a gay beach in Spain in August and how it got very intense, first in person and then via Facebook, Twitter, and Skype. Now the long-distance relationship has ended in a complicated mess. As a result, my friend says that he went for his first session with a psychotherapist. I tell him I am reviewing a book entitled Psychodynamic Perspectives on Working With Children, Families, and Schools. Many of the chapters in this collection make a distinction between psycho-counselling and psychotherapy. I ask him what he thinks might be the difference. Like me, he is not sure, but he is convinced that "counselling" is about helping individuals to "cope" and "get on with things," while therapy is committed to uncovering, discovering, root causes that have created patterns of behavior that may be described as harmful. In the case of my friend, he wants to find out, after yet another failed relationship, if he has an "attachment disorder" and if so why and how he can overcome it. Both my friend and this book lead me to believe that psychodynamic perspectives stem from the very human need to define, to understand, to categorize, to explain, and to know what is, perhaps, ultimately unknowable. This sense making is rooted in our innate need to sing, dance, and tell stories-in other words to celebrate and commiserate our very humanity.

This anthology is composed of 16 chapters, invited and edited by Michael O'Loughlin, an internationally known scholar who researches and writes about childhood and intergenerational trauma and psychosis. This book is part of a larger series edited by Jon Mills: The New Imago-Theoretical, Clinical, and Applied Psychoanalysis. To a reader like me, an academic and educator but not one immersed in psychoanalysis, this collection demonstrates just how fraught, fragmented, complicated, and controversial the landscape of childhood is, particularly for those whose jobs it is to study, mediate, and solve its problems and to do so without objectifying children as other, incomplete, or deficit.

Most of the chapters are based on clinical discussions of therapies and interventions in and out-of-school settings that derive from Freudian and Jungian understandings of the "self" in particular contexts. They also assume the reader has a basic understanding of Freudian and neoFreudian analysis, including attachment theory, concepts like transference and countertransference, and the role of the conscious and unconscious. It helps if readers are familiar with the work of Sigmund Freud, his daughter Anna, and of Jacques Lacan and others who have followed in their footsteps in attempts to theorize and to help particular children and families. This review provides an overview of a few of the chapters to give the reader a sense of the entire collection.

In the final chapter, "Progressive Education and Psychoanalysis: Towards a Theory of the Subjective Experience of School Life," American educator and school principal, Daniel Frank, argues:

Psychoanalysis, as a body of ideas about the meaning of being human and a method of inquiry into individual, group, and organizational experience, offers educators insights 
that can guide teachers toward understanding how students and parents, and how they themselves, experience school life. (p.317)

The concern of schools with both their personal and public selves leads Frank to discuss the "school romance project" in his school in Chicago. School life for individual students is an emotional experience organized around "idealization, disillusionment, and reparation....issues of ambivalence and identification join with feelings of conflict and love, aggression and creativity, fear and love (p.310).

Inspired by John Dewey's call in 1934 for a coherent philosophy of education in which "free individuals...through their own work, contribute to the liberation and enrichment of the lives of others" (p.312), Frank sees schools as sites of great hope and promise. He concludes that a psychoanalytic frame gives teachers tools "for encountering and working with the idealizations as well as the inevitable disappointments of everyday school life in a helpful and reparative fashion... [and] to recover and to repair from those moments of rift and rupture"(p. 317).

Derek Bunyard, in a chapter devoted to the work of French psychoanalyst Francoise Dolto, discusses her contribution to what he calls "the pre-institutionalization of early childhood" (p. 66). Bunyard usefully describes the post-Freudian, post-WWII schisms in psychoanalysis: Dolto was associated with the work of Jacques Lacan; Melanie Klein had her own followers, as did Anna Freud. In the 1950s, all of these individuals conducted research and therapy with children, something that Freud himself had never done. By the seventies, psychoanalytic studies were in steep decline. Bunyard attributes this to the increase in "the acceptance of the power of pharmacological products to directly influence brain and sensory function" (p.67). In addition, the sixties and seventies saw the rise of many academics' fascination with Lacan's theories of the imaginary and the symbolic, and the agency of language in disciplines like media and film. Thus, both cultural studies and mood-altering drugs "were corrosive of the social project of psychoanalysis" (p. 67). Even the construct of the traditional family on which much Freudian and neo-Freudian theory was built was changing rapidly and the "given" structure of the Freudian psyche began to seem less secure, particularly in relation to new ideas about gender and sexuality" (p. 67).

Dolto herself was an ardent Christian as well as a Freudian and saw Christ as "an emblem of the possibilities of desire" (p. 76). Bunyard quotes Ricoeur to contextualize this apparent contradiction: "If analytic experience is desire coming to discourse...the truth claims of psychoanalysis can legitimately be placed within the field of intersubjective communication" (p.82). In this way, psychoanalysis is akin to storytelling, "to reorganiz[ing] facts into a meaningful whole" (p. 82). We make it up, so-to-speak, in order to understand ourselves.

Dolto is known for setting up La Maison Verte, preschool sites in France where young children and their principal caregivers would work closely with psychologists to make "safe and unthreatening initial encounters with the exigencies of social life outside of the family." Language, mediation, and mutual respect and reciprocity were all "taught" in an unstructured but highly supportive environment.

The educational task was to assist each child to achieve his or her own form of unique social meaning and social responsiveness; but in fact in most cases she thought educational systems did exactly the reverse. (p. 85) 
Dolto's work is not related to neonate and infant cognitive development. Her lasting contribution to the field of psychodynamics was "truth saying": "a duty to speak from the heart, and for the heart, conferring a greater under-standing of the heart" (p. 86).

Editor Michael O'Loughlin's own contribution to the book is "Ghostly Presences in Children's Lives: Toward a Psychoanalysis of the Social." His chapter is concerned with how the subjectivity of each child is influenced, often for the worse, by the "anxious internalization of parental desire as their demand" (p. 93). Referring to a trauma from his own childhood, O'Loughlin cites what Christopher Bollas calls "an unknown known - knowledge that we know in some experiential sense but that we do not yet know that we know" [cognitively] (p. 95). This chapter also discusses subjectification ("coming to be") and subjection (the making of the subject) as children edge toward a world outside self through language and culture. He speaks, too, of Derrida's term "hauntology" - "inter-generationally transmitted forms of embodied knowledges — often traumatic ancestral experiences" (p.97). A chapter on the catastrophic impact of Indian Residential Schools in Canada on subsequent generations would have been highly appropriate in this collection to highlight "trans-generational traumas" (p. 106) to which O'Loughlin refers. He does cite the early childhood work being done at Gnibi College of Indigenous Australian Peoples where "evocative pedagogy" and "regenerative curriculum" for children with elders is used "to evoke the spectral memory of both past injury and ancestral knowledge" as children come "to fully identify with the origins of their own coming-to-be" ( $p$. 114).

Norma Tracey contributes the next chapter, "Working at the Interface of Education and Trauma in an Indigenous Pre-school: The Importance of 'Deep-Soul Listening." She discusses the dynamics and realities of working with Aborigine families in the outback of Australia where huge distances, small populations, systemic and overt racism, and grinding poverty pose particular challenges for children and their caregivers. Building trust and a sense of community is difficult but benefits both mothers and children.

Karen Ilinanoa explores this topic in more detail in the following chapter entitled "The Family Unconscious." Drawing on Samoan and Maori story-telling techniques and the recounting of dreams, the author laments the dismantling of the extended family system and the resulting deterioration of individual, family, and community health; increased stress on family dynamics; and the creation of deficits and pathologies in young children.

At the other extreme, are children, usually from middle-class environments, who suffer what Brazilian authors Ana Archangelo and Fabio Villela describe in their chapter as the "excessive presence" of parents. In North America, we sometimes refer commonly to this phenomenon as "helicopter parents" (hovering closely nearby) or "snowplow parents" (pushing all obstacles out of the way for their children). Other parental behaviours that delay the psychological growth of children include "the permanent complaint," which serves to enforce the alienation of the child from the school. More disturbing are "neglected and traumatized parents...[who] turn themselves into negligent, traumatizing parents" (p.196). The authors conclude their discussion of school-family relationships by reminding us that school for parents is much more than the functions and purposes explicitly outlined. Parents connect to their own children's experiences of schooling through their own experience of schooling. Their past experience is loaded with positive and/or negative emotions. On such a foundation, the possibility for a lack of a sense of belonging and of estrangement of the family from the school is 
high and needs to be countered by clear, open communication and the development of trust regarding the best interests of the child as a shared responsibility.

Only one chapter is not written from a specifically psychodynamic perspective: "The Child, Childhood, and School" by Patrick Lewis. Lewis is blunt in saying that "the psychology of human development...has evolved from "a process of a description of childhood to a prescription of childhood" (p. 39). Influential documents, tests, and inventories used in educational practice, such as Developmentally Appropriate Practice have "facilitated the creation of a prescribed childhood and adolescence" (p. 40). Developmental norms based on biomedical assumptions about cognition ignore the social and affective elements of literacy. Citing Bakhtin, Lewis notes that in terms of school literacies, "context always takes primacy over text" (p.40). Increasing emphasis and reliance on high stakes standardized testing across educational jurisdictions compounds the problem.

Yet in all of the rhetoric about early learning, improving education, standards, and practice where is the notion of the child as a person, a subject, a self in relationality with her family and the teacher? (p.41)

A technical, rational, and pseudo-scientific approach to teaching and learning uses "mythic norms" of developmental psychology to bolster attention to "standards, indicators, and outcomes" and an "absence of attending to each child's pains, joys, and desires" (p.43). Before telling a story, "The Red Ones are Best," about Kody, the crayon-eating, six-year-old, Lewis asks, "Can schools become sites of reciprocity in and through an assessment of care?"(p. 44). The rest of this chapter explores the power of story, narrative, and imagination, as ways of teaching, learning, and knowing. Lewis writes, "The world as created by adults is fraught with mystification from a young child's standpoint" (p.48). If we are to re-imagine schooling as truly child-centred, concludes Lewis, we must loosen our allegiance to the norms and standards entrenched in developmental psychology. However, that requires us "to welcome and embrace that which is given afresh through the daily wonderment of the young" (50).

I have tried in this review to illustrate that the intention of psychodynamic perspectives on learning is humanistic. It is an attempt, in the best interests of the child, to understand and resolve a variety of complex problems. Unfortunately, the labeling of distress and trauma can lead to the creation of a pathology in search of a cure. Psychodynamic perspectives position themselves, however, as counter narratives to the neo-liberal agenda that chooses to present schooling in terms of efficiencies, inputs, and outputs. "Test-taking or test-failing factories" is what Daniel Frank, contributing author, calls such schooling in the forward to this volume. He also refers to Franz Alexander, the founding director of Chicago's Institute for Psychoanalysis who, like John Dewey, "knew long ago [that] the future of democracy rests in the emotional maturity of its citizens to think critically, reflect thoroughly, and act empathically" (p. ix). Frank concludes:

These essays improve our capacity to understand the ways emotions are embedded in how human beings, young and older, organize our subjective experience of learning and teaching in schools. (p. x) 


\section{Reference}

O’Loughlin, M. (2013) Psychodynamic perspectives on working with children, families, and schools. Plymouth, UK: Jason Aronson Publisher. 